\title{
LETTER
}

\section{Cytomegalovirus reactivation in critically ill burn patients: it's time to worry about it!}

\author{
Julien Bordes ${ }^{1,2^{*}}$, Philippe Goutorbe ${ }^{1,2}$, Ambroise Montcriol $^{1,2}$, Henry Boret $^{1,2}$, Eric Dantzer ${ }^{2}$ and Eric Meaudre ${ }^{1,2}$ \\ See related research by Heininger et al., http://ccforum.com/content/15/2/R77
}

Cytomegalovirus (CMV) reactivation is widely documented in non-immunosuppressed critically ill patients and was reported in a previous issue of Critical Care to be associated with poor outcomes [1]. Although the question of the causative role of CMV remains under debate, a clinical trial aiming to evaluate the efficacy and safety of prophylactic treatment for prevention of CMV reactivation in immunocompetent patients in critical care has started [2].

To date, few data on patients with burns have been published. However, we know that patients with burns are predisposed to herpes virus infection and that they are good 'candidates' for CMV reactivation. As expected, data show a high CMV reactivation rate in patients with burns, from $55 \%$ to $71 \%$ [3,4]. Moreover, CMV reactivation seems to be intense, as $67 \%$ of patients reactivated CMV with a plasma viral load of greater than 1,000 copies/mL and $33 \%$ did so with a viral load of greater than 10,000 copies $/ \mathrm{mL}$ in the study by Bordes and colleagues [4]. However, available data in the literature are extracted from a subgroup of 20 patients with burns among a cohort of 120 critically ill patients for the study by Limaye and colleagues [3] and from a cohort of 29 patients with severe burns for the study by Bordes and colleagues [4].

These preliminary results emphasize the fact that it is absolutely necessary to better investigate the natural history of CMV reactivation in burns, as antiviral prophylaxis is being evaluated in critically ill patients. Indeed, if antiviral therapy is proved to be efficient on the CMV reactivation, should we treat more than $50 \%$ of our burn patients with antiviral treatment?

That is why we think that CMV reactivation still has to be studied in patients with burns, with the aim of answering the following questions:

\footnotetext{
* Correspondence: bordes.julien@neuf.fr

'Department of Intensive Care and Anesthesiology, Teaching Military Sainte Anne Hospital, BCRM Toulon, BP n600, 83800 Toulon Cedex 9, France ${ }^{2}$ Burn Care Center, Teaching Military Sainte Anne Hospital, BCRM Toulon, BP n600, 83800 Toulon Cedex 9, France
}

- Is CMV reactivation as frequent as previously reported in patients with severe burns?

- What are the risk factors for CMV reactivation in patients with burns?

- Is CMV reactivation associated with a poor outcome?

- And is there a quantitative association between CMV reactivation and poor outcome?

The community of burn caregivers should promote large and prospective cohorts of patients in order to investigate CMV reactivation in severe burns as a first step to support the potential indication of antiviral therapy in the coming years.

\section{Abbreviation}

CMV: Cytomegalovirus.

\section{Competing interests}

The authors declare that they have no competing interests.

Published: 25 Feb 2014

\section{References}

1. Heininger A, Haeberle H, Fischer I, Beck R, Riessen R, Rohde F, Meisner C, Jahn G, Koenigsrainer A, Unertl K, Hamprecht K: Cytomegalovirus reactivation and associated outcome of critically ill patients with severe sepsis. Crit Care 2011, 15:R77.

2. Millar J, Park SC, Cowley N, Moss P, Osman H, Bion JF: Anti-viral prophylaxis for prevention of cytomegalovirus reactivation in immunocompetent patients in critical care [abstract]. Intensive Care Med 2013, 39(suppl 2):201-539.

3. Limaye AP, Kirby KA, Rubenfeld GD, Leisenring WM, Bulger EM, Neff MJ, Gibran NS, Huang ML, Santo Hayes TK, Corey L, Boeckh M: Cytomegalovirus reactivation in critically ill immunocompetent patients. JAMA 2008, 300:413-422.

4. Bordes J, Maslin J, Prunet B, D'Aranda E, Lacroix G, Goutorbe P, Dantzer E, Meaudre E: Cytomegalovirus infection in severe burn patients monitoring by real-time polymerase chain reaction: a prospective study. Burns 2011, 37:434-439.

$10.1186 / \mathrm{cc} 13742$

Cite this article as: Bordes et al:: Cytomegalovirus reactivation in critically ill burn patients: it's time to worry about it! Critical Care 2014, 18:410 